\title{
IDENTIDADE E MEMÓRIA FRONTEIRIÇA: O CHIBO, O TRABALHO DE SUBSISTÊNCIA OU A PRÁTICA CULTURAL?
}

\author{
Identity and Border Memory: The Chibo, Work of Subsistence or Cultural \\ Practice?
}

\author{
Marilce Auxiliadora Palaoro MARI - UNIOESTE ${ }^{1}$
}

\begin{abstract}
RESUMO: Este artigo foi desenvolvido a partir das informações de quatro entrevistados de San Antonio-Argentina, quatro de Santo Antonio do Sudoeste-Brasil e de populares que moram próximo às margens do Rio Santo Antonio, que delimita a fronteira geográfica e política de ambos os países das duas localidades. O objetivo deste artigo é registrar a memória dos sujeitos fronteiriços identificando suas narrativas e socialidades, no que se refere aos "chibos" e "piques". Para responder aos questionamentos da investigação foram usadas as entrevistas narrativas, a partir da alocução "ser fronteiriço é...", e anotações no diário de campo da pesquisadora. Concluí que o local pesquisado é um espaço social formativo, em que os argentinos e brasileiros estabelecem trocas no cotidiano. A identidade se (re) afirma nas diferenças culturais dos sujeitos fronteiriços. A memória toma o papel de mediadora entre o passado e o presente que aflora nas narrativas dos entrevistados apresentando traços de hibridismo na linguagem e nas interações sociais próprias deste local de fronteira, e por meio das relações entre os chibeiros e moradores das duas localidades estudadas.
\end{abstract}

PALAVRAS-CHAVE: Identidade. Fronteira. Chibo. Piques. Memória.

ABSTRACT: This article was developed from the information of four interviewees from San Antonio-Argentina, and four from Santo Antonio do Sudoeste-Brazil, and from people living near the banks of the Rio Santo Antonio, which delimits the geographical and political frontier of both countries of the two locations. The objective of this article is to register the memory of the frontier subjects identifying their narratives and In terms of "chibos" and "piques". In order to respond to the research questions, the narrative interviews were used, from the address "being frontier ...", and journal entries of campo. We conclude that the place searched is a formative social space, in which Argentines and Brazilians establish daily exchanges. Identity is (re) affirmed in the cultural differences of the subjects border crossings. Memory plays the role of mediator between the past and the present that appears in the narratives of the interviewees presenting traces of hybridity in the language and in the social interactions of this locality of frontier, and through the relations between the chibeiros and residents of the two studied localities.

KEYWORDS: Identity. Border. Chibo. Memory.

\footnotetext{
${ }^{1}$ Mestre em Educação pela Universidade do Oeste do Paraná. Atualmente é professora de Língua Espanhola e Língua Portuguesa na Secretaria de Estado da Educação.
} 


\section{INTRODUÇÃO}

Habitar a zona fronteiriça que se localiza Santo Antonio do Sudoeste e San Antonio é conviver em um local, em que o movimento de ir e vir entre cidadãos argentinos e brasileiros torna-se parte do cotidiano desta fronteira. Ter crescido no município de Santo Antonio do Sudoeste, me permitiu estar nesta condição singular: a de ser fronteiriça. Tal situação foi percebida, à medida que os contatos sociais próprios deste lugar se estabeleceram, bem como a partir das reflexões sobre tal questão.

Percebi por meio dos autores como Ecléa Bosi (1998), Jaques Le Goff (1992) e Marilena de Souza Chauí (2000), a possibilidade de aprofundar os estudos sobre a vida dos fronteiriços, suas relações, cotidianeidade e vivências.

Para dar a conhecer o campo de pesquisa, convém fazer breve apresentação do lócus da investigação. O município de Santo Antonio do Sudoeste está localizado no Extremo Sudoeste do Paraná, que faz divisa com San Antonio, localizado no Extremo Leste da Argentina, cujas localidades co-irmãs têm o Rio Santo Antonio como limiar de marcação que separa (ou une) os dois municípios. Conforme Mari (2002, p. 38) este foi navegável desde o ano de 1759, conforme Ata de Inauguração do Peperi-Guaçu, atual cidade de Dionísio Cerqueira, (SC). Tal rio baliza a vida entre as duas localidades e, por vezes é considerado limite entre as duas nacionalidades.

No passo fronteiriço oficial, a transposição é feita, tanto de um lado, quanto do outro, através de uma ponte de concreto. Nos outros pontos de locomoção entre o território fronteiriço de um município e outro, os habitantes das duas localidades, usam com frequência os piques para transpor o rio. É possível encontrar dezenas deles, que são estreitas passagens abertas na mata fechada, ou na mata rala, ou apenas no gramado que é o caso dos piques que estão localizados próximos aos bairros em que a mata, em ambos os lados, foi derrubada, restando apenas poucas árvores na beira do rio. Além desses, existem os piques mais largos em que passam caminhões, tratores, carroças, utilitários entre outros, porém estes não desembocam no Rio Santo Antonio, apenas avançam a cerca de arame farpado entre a linha de fronteira em ambos os lados.

Os piques formam um conjunto de trilhas, com uma infinidade de bifurcações como se fosse um mosaico, sem que se possa saber onde é o inicio e o fim de cada um. Para este trabalho investiguei seis desses trajetos, que são passagens por terra. Os 
demais em número de sete, se interligam e desembocam nas margens do rio formando um desenho intrincado do limite entre os dois países e margeiam o Rio Santo Antonio.

Os piques são assim nominados pelos populares, e moradores dos arredores: Pique da Pedreira 1: é o pique "visado pela acessibilidade", tanto da parte dos chibeiros que passam com cargas vultuosas em valores, bem como pela Polícia Federal e Gendarmería Nacional, que controlam o tráfego ilícito. O pique do seu Biriva se localiza na Linha São João, e do seu Baez, está localizado na Linha São Mateus próximo ao marco fronteiriço, e o do seu Midio na Linha Calvário. O pique do Cerro Sete se localiza na Linha Cedro e o Pique da Nascente, na Linha Tarumã, acima do marco onde nasce o Rio Santo Antonio. Esses piques tem "a linha“ que define a fronteira entre Argentina e Brasil por terra, separada apenas por uma cerca de arame farpado, o que facilita a passagem entre os dois países.

Já o pique da Nascente 2, é o primeiro dos que tem o Rio Santo Antonio como delimitador da fronteira geográfica, e este está próximo da nascente do rio. Os outros são: o Pique da Pedreira, Pique do Tenente 1, localizado na Linha Tarumã. O Pique do Tenente 2 e o Pique do Tenente 3, se localizam nas imediações do Bairro Princesa Isabel, já o Pique da Cigana está localizado próximo ao Bairro Vila Nova, e o Pique do Fumeiro localizado no Bairro Entre Rios, e o Pique do seu Telmo nas proximidades da estação de esgoto do Bairro Jardim Fronteira.

Todos eles demonstram as formas de apropriação mobilizadas cotidianamente pela população que vive nas duas localidades.

Nesse contexto, o sujeito fronteiriço se reconhece ao se perceber vivendo em uma posição geográfica confinante, mas também ao estar sujeito a contatos e influências que impactam a formação da identidade das pessoas que vivem nesta fronteira.

Dentre os elementos que representam o universo fronteiriço, a língua portuguesa do Brasil e a língua espanhola da Argentina, apresentam novos contornos na sua construção, o hibridismo deixa de ser um conceito distante e ganha familiaridade na vida dos sujeitos que vivem ali. Neste ambiente, a maneira de vestir, os pratos que são elaborados para a alimentação, as bebidas ingeridas, a forma do falar, o sotaque, a mistura entre os idiomas, representam a identidade fronteiriça e "[...] adquirem sentido por meio da linguagem e dos sistemas simbólicos pelos quais elas são representadas" (WOODWARD 2000, p. 5). A mescla das línguas, não resulta em um terceiro idioma, mas numa terceira linguagem, o portunhol, mistura de português com espanhol, e que a maioria dos fronteiriços pratica para dialogar, criar proximidade, para negociar e suprir 
necessidades práticas de sobrevivência, para demarcar trocas culturais e para experimentar a vida nas diferentes feições do afeto (no sentido do ser afetado por outrem, isto significa que o sentimento pode ser de atração ou repulsão), nas diversas situações e lugares em que as pessoas entram em interação tais como: postos de migração, nas escolas, e nas instituições dos poderes constituídos.

Ao cruzar a ponte, em direção a San Antonio, por mais que a natureza seja a mesma e não há diferença entre as árvores e a grama que crescem nas duas barrancas do rio, ao transpô-la, percebo uma gama de elementos que sinalizam o território argentino, entre eles: o cheiro dos produtos a venda no comércio, as pessoas caminhando nas ruas com uma garrafa térmica embaixo do braço e a cuia do mate na mão, o uniforme dos funcionários da SENASA ${ }^{2}$, da Migração e da Gendarmería $^{3}$, os quais são alguns elementos de identificação dos argentinos de San Antonio.

Nessa localidade, são muitos os sinais indicativos do que referimos anteriormente. Essa conexão pode ser percebida nos postes de luz de madeira, na fraca iluminação pública, nos quebra-molas côncavos, na aparência das casas. Na madeira que substitui as chapas de zinco e luminárias, utilizadas nas propagandas e indicações do comércio, nos pontos de referência de colégios e similares. Tais marcações são indícios das diferenças que se mostram nos artefatos utilizados e que permitem reconhecer o que é produzido por um ou outro país.

Ademais não é incomum para os brasileiros que frequentam San Antonio ouvir o som da cumbia ${ }^{4}$ propagada pela aparelhagem dos veículos, das casas, e dos pontos de comércio no final de tarde. Em outras ocasiões sentar num bar para tomar cerveja argentina, e ouvir música sertaneja brasileira, ou assistir partidas de futebol dos campeonatos brasileiros nas televisões ligadas no comércio argentino de San Antonio. Como é possível perceber há marcadores que indicam a diferença e da mesma forma indicações que ressaltam a justaposição em que ações são partilhadas pelos viventes das duas localidades.

\footnotetext{
${ }^{2}$ SENASA: Servicio Nacional de Sanidad y Calidad Agroalimentaria.

${ }^{3}$ Gendarmería Nacional Argentina: Força de Segurança de natureza militar vinculada ao Ministério do Interior que atua no controle e defesa das fronteiras territoriais argentinas.

${ }^{4}$ Cumbia: é a música típica nacional da Colômbia. De início, surgiu nos guetos das grandes cidades colombianas, sendo que até hoje é uma categoria popular da música. O ritmo se disseminou por todos ou quase todos os países falantes do castelhano na América Latina e, atualmente, é considerado um dos ritmos musicais mais populares na Argentina e em outros países vizinhos. A cumbia é um estilo de música tradicional da Colômbia e Panamá, e uma dança popular de distintos países latino-americanos.
} 
Tais fatores fazem com que se perceba o quão artificial podem ser as fronteiras, visto que o por do sol por trás das araucárias parece conferir certa unidade ao caos linguístico e cultural que reconheço, e que interponho questionamentos.

No mesmo sentido, evoco as palavras de um dos entrevistados, Juan Benitez quando diz “[...] ser fronterizo es un sentimiento, un sentimiento muy especial porque sólo sabe quien vive en la frontera" (entrevista em 08/02/2015).

Se há diferenças, encontrei também semelhanças que para além do cumprimento um "hola que tal", ou, um "oi tudo bem", de sotaques misturados, escondem dores, angústias, problemas, alegrias. Por momentos também somos só proximidade, pois por vezes partilhamos os sonhos, a labuta diária, a fé, a desesperança, as histórias de vida distintas que aprendi ao conviver com as pessoas com quem conversei para a produção deste trabalho, e que passei a visitá-las e escutar as histórias de vida de seres humanos, que desdenham da ideia de identidade nacional, fazendo ver homens, mulheres, crianças que, rasurando a identificação inventada, são tão somente pessoas em processo de inventar a própria existência.

Ao estudar e observar a língua espanhola e a cultura dos vizinhos hispanohablantes percebo que o idioma português é entrecortado por expressões, palavras e nomes próprios pronunciados em língua castelhana. Tive a certeza que com os habitantes de Santo Antonio do Sudoeste e San Antonio não cruzavam apenas a ponte sobre o rio, ou não atravessavam o limite fronteiriço através dos piques, acompanhava-os também os costumes, a língua, sempre pronta a interpelar nos mais diferentes momentos e nas mais variadas formas.

A convivência com amigos de San Antonio, as discussões sobre assuntos triviais, as festas entre amigos que se dedicam às artes e a cultura após o dia de trabalho. O modo peculiar de se viver na fronteira me instigou a pesquisar a identidade cultural, e a memória em Santo Antonio do Sudoeste e San Antonio.

Vem da experiência de vivente na fronteira o interesse em escrever sobre a identidade e memória fronteiriça, bem como me instiga a adentrar no mundo dos chibeiros e suas relações nas duas localidades, registrar a memória dos sujeitos fronteiriços identificando suas narrativas e socialidades, no que se refere aos "chibos" e "piques". E por meio da alocução, ser fronteiriço é..., este trabalho tentou identificar formas de interação experimentadas pelos sujeitos que circulam nas localidades referidas neste trabalho, e os processos de construção da memória e identidade pelos sujeitos da pesquisa. 
A composição deste trabalho discorre sobre os depoimentos memorialísticos dos sujeitos pesquisados os quais retratam o uso dos piques, a realização dos chibos, os produtos transportados de um lado ao outro da fronteira, e registra a diferença entre chibos e contrabandos, numa fronteira que o silêncio fala mais alto do que a ação das polícias dos dois países fronteiriços.

\section{CHIbO, CHIBEAR, CHIBEIO, CHIBEABA, ChIBEANDO. VERbo? TRABALHO DE SUBSISTÊNCIA OU PRÁTICA CULTURAL?}

No espaço fronteiriço, de Santo Antonio do Sudoeste e San Antonio, o chibeiro ${ }^{5}$ ocupa um lugar no mínimo curioso, senão interessante. Foram raras as pessoas com quem conversei e entrevistei que não se referiram ao chibo, ou ao chibeiro. Sobre ele, ouve-se incontáveis histórias e lendas. Quem é o chibeiro? Personagem saudosista, contando histórias do passado e que circula entre um lado e outro da fronteira entre Santo Antonio do Sudoeste e San Antonio? É o comprador de mercadorias de um lado e outro da fronteira?

Não pretendo aqui exaltar a figura do chibeiro, nem julgar se o que ele realiza é lícito ou não, nem mesmo discutir o trabalho enquanto uma categoria para pesquisa, mas registrar essa figura que aparece na maioria das conversas com os entrevistados e populares, bem como na memória dos fronteiriços com quem tenho conversado no decorrer do processo investigativo.

Conforme artigo "O Chibo", o relato é o seguinte: "a história do chibo, esse "cabrito", em castelhano, confunde-se com o gaúcho da fronteira, principalmente de Uruguaiana. O chibo foi muito usado no contrabando do charque, e um dos motivadores das Guerras dos Farrapos" (JORNAL A TRIBUNA, 2009, p.7), seria possível afirmar que o chibo desta região fronteiriça é a herança dos fugitivos da Guerra dos Farrapos, que segundo Dambros (1997) se esconderam nestas matas em busca de segurança?

Em entrevista, Elizandro Pellin assim se manifestou sobre a temática,

Hoje o chibo ainda existe.[...] Termo vindo do Rio Grande do Sul. Quilero é o equivalente ao chibero mas na fronteira com o Uruguai, onde nós falamos na Argentina é o chibero e aqui era o exemplo do ponto informal do chibo. A

\footnotetext{
${ }^{5}$ Chibeiro: Refere-se à pessoa que pratica o comércio "formiga", o leva e trás de mercadorias úteis, sem o propósitode formação de comércio organizado ou em escala.
} 
nossa fronteira exatamente é do chibo inofensivo. É por uma questão de sobrevivência (PELLIN, 2015, não publicado) ${ }^{6}$.

Conforme o Sr. Pellin, os chibeiros faziam o chibo para manutenção familiar, principalmente na época da colonização desta zona fronteiriça. Superaram as limitações geográficas, burlaram a burocracia estatal e até a vigilância da Gendarmería da Argentina e do Posto da Receita Federal no Brasil. Conforme depoimentos de filhos de antigos chibeiros, como contação de façanhas dos pais e avós, disseram que em determinado dia foram pegos de surpresa pelos homens da Gendarmería de San Antonio. Tal situação, fez com que deixassem tudo para trás e se embrenhassem na mata. Mas não aceitaram passivamente terem perdido os cavalos para os gendarmes. $\mathrm{O}$ que mais os deixou revoltados era imaginar os cavalos de estimação, companheiros e cúmplices na travessia do Santo Antonio nos inúmeros chibos que já tinham praticado, serem vendidos em troca de favores para outros chibeiros. Acordaram entre eles, e em uma noite sem luar, roubaram os cavalos que lhe pertenciam do pátio da gendarmería em San Antonio.

Sobre o chibeiro, essa figura que compõe a memória dos populares desta zona de fronteira ouvi causos nas rodas de mate, e nos churrascos e "asados"7 em ambas as margens do Santo Antonio, em que as pessoas disseram que os chibeiros aproximam os fronteiriços por meio do comércio, da linguagem, e até mesmo dos filhos que geram e que falam duas línguas. Produzem valores humanos e culturais. Afirmaram ainda, que os chibeiros elegem formas mais práticas e negam a burocracia, como por exemplo ao chibear defuntos. Tal declaração fez com que voltasse a procurar o chibeiro anteriormente entrevistado, Anderson Borba, para conseguir mais informações a partir de suas narrações.

Ele expôs um fato que marcou sua vida nos chibos, e transformou tal experiência em uma poesia, que se refere à morte de uma mulher brasileira em terras argentinas.

[...] Meu companheiro de chibo, me pediu desesperado, que eu fosse até o outro lado, pois sua esposa morreu, ela sendo brasileira, para cruzar a fronteira, foi preciso recorrer, e provar dentro da lei, com papéis ao consulado, pra desespero do marido, lhe foi negado o pedido, e teria que esperar, foi quando surgiu a ideia, se for pra esperar por eles, então nós vamos chibear, lembro como se fosse agora, estacionei a rural lá fora, e colocamos o corpo dentro, o meu sangue ficou frio, quando eu cruzei o rio,

\footnotetext{
${ }^{6}$ PELLIN, E. Dissertação de Mestrado. Santo Antonio do Sudoeste, 2015. Não publicado.

${ }^{7}$ Asado: o mesmo que churrasco na língua portuguesa.
} 
com aquele corpo sombrio, que jazia, já frio, ao lado do meu assento (BORBA, 2015, não publicado) ${ }^{8}$

O poema expressa uma situação trágica quando uma brasileira morre no lado da fronteira Argentina. Diante das exigências burocráticas o marido é colocado frente à necessidade de decidir entre aguardar a liberação do corpo de sua esposa para depois trazê-lo para o Brasil (a experiência dos viventes no local indicava que esta não era uma solução viável) ou achar uma forma de trazê-la contornando as leis que regem a vida no lugar. Tomada a decisão de enterrá-la no Brasil exigiu do marido recorrer a um chibeiro conhecido, e transportar o corpo inerte da esposa, tal como fazia com as mercadorias. No poema percebi que, embora o perecimento da mulher deixasse o chibeiro inquieto, o desejo do marido em enterrá-la no seu lugar de vida dominou a sua decisão: transportar o corpo gélido. Trazê-lo para sua morada final.

O fato narrado parece descrição de acontecimentos surreais que acompanho na literatura. No entanto é uma expressão que demonstra a importância e o significado social do chibeiro. Assim, os chibos denotam a aproximação das pessoas, a cumplicidade, a parceria, a proximidade que existe entre os moradores e aqueles que transportam mais que mercadorias.

Conforme populares que residem próximos aos piques, existem os chibos "inofensivos ou normais", que são itens que na Argentina são mais baratos, o óleo, gás de cozinha, sucos, ração para cachorros e gatos, peças de carros, madeiras para construir casas, palanques para construir cercas de potreiros e mangueiras para o gado, entre outros, sem muita importância para eles. Do Brasil sai a carne de frango, o arroz e o café, e alguns móveis para decorar a casa. Disseram que os móveis do Brasil são mais bonitos, então são comprados e "passados" pelos piques, descarregados dos veículos de transporte pelas próprias lojas que os vendem. Às vezes os descarregadores da loja ajudam os compradores argentinos passar pelos piques, outras vezes não se faz necessário, pois o próprio comprador leva “ayudantes" para atravessar a fronteira.

Um morador próximo do pique da Pedreira 1, disse que existem piques "em atividade" que são usados para atravessar cargas que envulta muito dinheiro, contou também que os donos das cargas, sabem quando a policia e a gendarmería vão estar nos piques. Disse também que as autoridades, só podem prender a carga com o caminhão,

\footnotetext{
${ }^{8}$ BORBA, A. Dissertação de Mestrado. Santo Antonio do Sudoeste, 2015. Não publicado.
} 
carreta, trator, ou o gado quando "atravessado" pelos piques, quando o chibo estiver "em cima da linha", ou seja, o espaço que define onde é o território brasileiro, ou o argentino, direcionados pelos marcos fronteiriços. Se ele estiver a qualquer distância da tal "linha", eles não podem fazer a apreensão pois alegam o direito de ir e vir. Conforme palavras do tal morador, ele já ouviu tiros sendo trocados por chibeiros, em que estes imaginavam ser a Polícia Federal ou a Gendarmería Nacional. Disse, “isso é raro acontecer, mas já aconteceu."

Ademais, ao observar o movimento nos piques é possível concluir que existe um terceiro envolvido, a testemunha que silencia. Os moradores das margens do Santo Antonio sabem o que é atravessado, enviado, transportado, através do rio, mas não falam, não contam. Preferem silenciar e reconhecem mesmo de forma inconsciente as "tensões" em que vivem os que chibeiam, e os que sabem dos chibos no entorno do rio. Nesse contexto Martins (2009, p. 25) escreveu que, “[...] inevitavelmente se reconhece que a situação de fronteira é uma situação de conflito". Segundo conversas com os moradores que residem próximo aos piques, os chibeiros e as testemunhas, são cúmplices, pois participam dos chibos silenciando quando são indagados pela polícia ou gendarmería, ambos sabem que o chibo é uma forma de ganhar a vida, mesmo correndo riscos pois é ilegal.

De um, e outro lado do rio, os chibeiros realizam negócios que envolvem brasileiros e argentinos, e conforme disseram os chibeiros na roda de um churrasco, "a gente sabe que não é uma transação dentro da lei, mas nós precisamos trabalhar". Tais transações, conforme Certeau (2013, p. 86) "se repetem e se reforçam uma a outra". Conforme palavras de moradores próximos ao rio Santo Antonio, é uma maneira de aproveitar as oportunidades que o câmbio apresenta e a facilidade por outro lado de vender os produtos por um preço mais atrativo. Os brasileiros compram em peso, e os argentinos recebem em real.

O movimento do chibo, a passagem pelos piques, denota a criação de laços comerciais e culturais. Ao indagar os populares que vivem nas margens do rio, e próximos a diferentes piques, disseram conhecer os chibeiros, e que todos os respeitam, sabem da sua existência, e que são trabalhadores, vivem em sociedade e não estão roubando, apenas comprando e vendendo por preços que convém ao próprio bolso.

Mas na fronteira, também há registro do uso da violência para manutenção deste comércio. Isso foi o que disse uma senhora brasileira, moradora nas proximidades de um pique, enquanto tomava mate argentino, na cuia brasileira, e que continuou sua 
prosa. Afirmou que certa data, um agricultor brasileiro que morava no outro lado da cerca, na Argentina, trouxe uma carga de soja em um caminhão para ser comercializado no Brasil. Um determinado sujeito, que ela não citou o nome, matou o dono da carga e repartiu a carga com o motorista do caminhão. Como a carga seria passada ilegalmente pelo agricultor, a família nem chamou a polícia pois teria que explicar o fato da carga ter saído sem nota fiscal, e o que estaria fazendo o agricultor atravessando a fronteira com a soja. Segundo ela, raramente isso acontece, porque os chibeiros se ajudam.

Ao pensar em tantos depoimentos dos populares, este, dessa senhora nos pareceu um fato isolado e não corriqueiro na "linha" dos piques.

Outros moradores, me disseram que há ocasiões que não é preciso palavras, basta um gesto, uma indicação, uma forma de comunicação que é decifrável para aqueles que partilham o local. Isso envolve cumprimentos, troca de informações sobre a localização da polícia ou da gendarmería, dentre outras. No mesmo sentido, Maffesoli, (2004, p. 34) corrobora o enunciado anterior ao escrever sobre,

Um saber do corpo individual e coletivo, no qual a felicidade e infelicidade,
jubilação e desamparo estão intimamente ligados. Saber do sem-triagem, que
não passa necessariamente pela conscientização ou a verbalização, mas
garantindo em longo prazo a perduração obstinada da vida. Ainda que ela
integre seu oposto: a morte e suas diferentes manifestações cotidianas.

Para o autor, o conhecimento que tenta captar esses contornos é significativo por que decide não desviar o olhar da vida e suas múltiplas manifestações. Faz exatamente o contrário, volta-se para o conjunto de acontecimentos cotidianos, que se perdem na infinidade de fatos banais. Nesse sentido, a vida ordinária é tudo o que interessa.

A facilidade do acesso aos meios de comunicação, também interfere nas negociações que ultrapassam a fronteira. Nesse sentido é exemplar a decisão das operadoras de celular brasileiras e argentinas que encurtam caminhos via satélite, favorecendo o comércio legal e clandestino, em que, na impossibilidade de usar o passo fronteiriço usam os piques para realizar as entregas das mercadorias. A situação relatada não constitui exceção, compõe as situações corriqueiras no local pois “o fronteiriço sabe que tem constantemente que jogar com os acontecimentos para os transformar em ocasiões" (CERTEAU, 2013, p. 46).

Se o olhar for voltado para outras temporalidades, será encontrada situação análoga. Na época da exploração da erva-mate no início do século passado, tal produto passava livremente pela fronteira, pois no Brasil não havia controle fiscal. Em Scarabotto, (2007, p. 34) isso pode ser exemplificado quando a autora afirma que "[...] 
desde 1929 já havia um posto fiscal administrado pela Secretaria de Fazenda do Estado do Paraná, na passagem de Santo Antonio do Sudoeste (BR) para San Antonio (AR)". Porém, conforme MORAIS, (1974, p. 13) a chegada de duas famílias paraguaias nesta fronteira foi em 1902. Portanto antes do posto fiscal ser instalado em Santo Antonio do Sudoeste, a erva mate, produto de comercialização da época já era extraída sem controle fiscal algum. Tal fato caracterizava chibo? Onde e quando o chibo se originou? Ao entrevistar o chibeiro Anderson Borba, ele nos fez lembrar o que Maffesoli, ( 2004, p. 67) escreveu: "a terra é um constante lembrete do ciclo da morte e da vida", ele está na terceira geração de chibeiros, seu avô sustentava a família com os chibos de farinha, querosene, banha, óleo de cozinha e sabão, o qual vendia para os moradores próximos, ele residia a aproximadamente vinte quilômetros da Argentina, saía de casa de madrugada e retornava em casa ao anoitecer.

O tom de voz, a postura corporal, o gesto das mãos, o olhar oblíquo, o sorriso dissimulado, a ansiedade que demonstra ao falar, são características deste homem que vive no cotidiano a insegurança de suas atividades laborais. Ele demonstra a "dualidade" entre a tranquilidade de estar em território brasileiro, "na nossa terra", o sentimento de pertencer à pátria brasileira, e o temor constante de estar no território do vizinho país, que por mais que o conheça, não é sua terra natal. Ele disse: "algum lugar tem essa terra seca" (BORBA, 2015, não publicado) ${ }^{9}$. Como se a terra fosse um terreno mais seguro do que a travessia dos piques por meio da água do rio Santo Antonio ou o temor expressado ao dizer: "quando eu fico sozinho no meio daquele campo aberto, ou que começa a escurecer" (BORBA, 2015, não publicado $)^{10}$.

Mas quem é o inimigo temido do chibeiro? A Gendarmería? A polícia argentina ou a polícia brasileira? Ou a falta de oportunidades de um trabalho formal que substitui o chibo para garantir a própria subsistência e da família?

Retomo Maffesoli, (2004, p. 50) quando descreve o sentimento de antítese que é possível perceber no chibeiro entrevistado, quando diz que "[...] o barroco. Já pudemos sentir-lhe os passos em numerosas culturas e diferentes épocas. Ao contrário de um espírito clássico, racional e mecânico, espírito redutor e funcional, o barroco é feito de conjunções, de sinergias, de polissemias".

\footnotetext{
${ }^{9}$ BORBA, A. Dissertação de Mestrado. Santo Antonio do Sudoeste, 2015. Não publicado.

${ }^{10}$ BORBA, A. Dissertação de Mestrado. Santo Antonio do Sudoeste, 2015. Não publicado.
} 
Nota-se o barroco expresso no movimento narrado pelo chibeiro Anderson Borba, sobre suas vivências quando ele diz:

\begin{abstract}
Você passa de um lado para o outro. [...] O povo de lá é o mesmo daqui. Ele vai me receber com o mesmo carinho, e o que ele tiver para comer, ele vai por na mesa, ele vai dividir comigo. Ser fronteiriço, é compartilhar essa alegria. Esse nascer e pôr do sol que só nós temos. Compartilhar o dia a dia, onde você passa de um lado para o outro. [...] Sempre trocando mercadorias, palavras. [...] É estar dividido mas ser o mesmo povo. [...] Isso vem de muitos anos. Aqui a gente não vive, convive. A gente aprendeu a respeitar e ser respeitado. Aprendeu a dividir, aprendeu a valorizar, a compartilhar muitas coisas nossas, muitas coisas deles, tanto nosso chimarrão como o mate argentino (BORBA, 2015, não publicado). ${ }^{11}$
\end{abstract}

Pergunto, o que o pôr do sol esconde por trás das cercas de arame farpado? Se pudessem o que contariam as margens do rio Santo Antonio? Na roda do mate e do chimarrão, as conversas são apenas causos triviais sobre o dia a dia, ou escondem intenções comerciais, planos para melhor utilizar as oportunidades de ganho fácil?

Se para Maffesoli (2004), o barroco é “conjunção", é "sinergia”, é “polissemia”, o chibeiro em suas palavras vai ao encontro do que escreve o autor. Ele retrata em sua fala a cooperação na convivência diária, as conexões que vão além de uma realização comercial, no ato de "compartilhar", "dividir" e nas vozes trazidas por ele através do tempo, quando diz que, "não faz pouco tempo que vive-se assim na fronteira". (BORBA, 2015, não publicado) ${ }^{12}$. No movimento contínuo, uniforme em seus paradoxos. No que vira o comum no cotidiano com as diferenças peculiares desta zona fronteiriça. No olhar de Martins (2009, p. 10), ele diz "tomo a fronteira como lugar privilegiado da observação sociológica e dos conflitos e dificuldades próprios da constituição do humano." O que os chibeiros e moradores de ambos lados da "linha" compartilham? Seriam informações? O que eles dividem? Seriam mercadorias? Que tipos de mercadoria?

É interessante dizer que os chibeiros, realizam o comércio de pouca monta, e para sobrevivência, não é o caso dos contrabandos. Tomo como exemplo a reportagem do Jornal Impacto On Line, em que traz a noticia de 02 de fevereiro de 2016 que diz:

Na manhã desta terça-feira, 02/02, a Delegacia de Polícia Federal em Dionísio Cerqueira, com participação da Receita Federal, deflagrou a

\footnotetext{
${ }^{11}$ BORBA, A. Dissertação de Mestrado. Santo Antonio do Sudoeste, 2015. Não publicado.

12 BORBA, A. Dissertação de Mestrado. Santo Antonio do Sudoeste, 2015. Não publicado.
} 
Operação "Formiga", dando cumprimento a 16 Mandados de Busca e Apreensão e 17 Mandados de Condução Coercitiva, expedidos pelo Juízo da $1^{\mathrm{a}}$ Vara Federal em Francisco Beltrão, nas cidades catarinenses de Dionísio Cerqueira e Xanxerê, e nas paranaenses de Barracão, Santo Antônio do Sudoeste, Francisco Beltrão, Marmeleiro e Curitiba. A investigação teve início em 2013, com a descoberta de um galpão no município de Marmeleiro onde eram estocados produtos trazidos ilegalmente da Argentina, principalmente vinhos e energéticos, para depois serem distribuídos para comerciantes brasileiros. [...] os principais envolvidos no esquema criminoso, em 23 meses de investigação, movimentaram aproximadamente R\$ 18.000.000,00 (dezoito milhões de reais) com a comercialização dos produtos descaminhados, o que importaria num prejuízo estimado de aproximadamente $\mathrm{R} \$ 4.800 .000,00$ ao erário, com a sonegação dos tributos federais Imposto de Importação e IPI. (JORNAL IMPACTO ON LINE, 2016).

Se o chibo é praticado todos os dias na fronteira, ele tem caminhos, direções. Todos eles têm ou terão sua bifurcação sobre o Rio Santo Antonio e em "cima da linha" que divide a terra seca, um tanto pedregosa, com capim ralo sobre ela, e que se encontra acima da nascente do Rio Santo Antonio, ou nas águas do Santo Antonio. Eis o que se apresenta como síntese do que seja ser o fronteiriço "comum", um sujeito do movimento, que vive e trabalha em um espaço poliestruturado, que forma sua identidade e memória e a cada dia inventa novos significados para a palavra polissemia.

\subsection{Os piques: caminhos e descaminhos dos chibeiros. Na intersecção de dois mundos, um terceiro.}

Não há como falar dos chibeiros sem dizer do conjunto de vivências que há por trás dos piques, no meio deles, onde um começa e outro termina. Os piques são associados diretamente aos chibos, e estes, neste caso à travessia da fronteira geográfica.

Mas o que realmente é um pique? Conforme dicionário da Língua Portuguesa (Aulete, 2011, p. 1069), "pique quer dizer trilha ou caminho mais curto aberto na mata, ação de correr, sair num pique desenfreado". Conforme significado pode-se imaginar a ação de quem usa os piques no movimento diário de locomoção entre uma localidade e outra. A própria origem da palavra denota movimento, pressa, astúcia.

No decorrer da pesquisa, percorri aproximadamente dez quilômetros margeando o rio Santo Antonio e atravessamos a fronteira pela passagem de terra, em que a demarcação é feita com marcos de concreto. O maior deles, próximo a nascente do rio, contém a inscrição da data de 1903. 
Fiz a travessia do rio em todos os pontos onde havia pinguelas, e caminhei pelas ramificações dos piques nas duas margens do Santo Antonio. Nestas idas e vindas, encontrei fronteiriços que dialogaram comigo. Entre tantos aspectos, constatei que mais argentinos se dirigem ao Brasil, do que brasileiros se dirigem a Argentina, provavelmente porque Santo Antonio do Sudoeste no momento atual economicamente é mais viável para os argentinos, pois paga-se o trabalho em reais, ao contrário de San Antonio que pagam a mão de obra e serviços em pesos argentinos.

Mas, qual é o olhar da gendarmería e das polícias de ambas as localidades? Quem é beneficiado com os chibos? Que outras relações existem com o comércio clandestino?

No trabalho investigativo dos piques, usei o Diário de Campo, em que registrei os principais produtos que são transportados através dos piques. Os brasileiros traziam de San Antonio: farinha, sabão, gás de cozinha, carne de gado, óleo comestível, fraldas para bebês, remédios, pneus, tinta para pintar casas, arame farpado e galletas ${ }^{13}$.

Do Brasil para a Argentina as pessoas transportavam, frutas, carne de frango, café, arroz, roupas, calçados, farofa industrializada, mudas de eucalipto, peças de carro, mudas de flores, e consegui registrar, até o transporte de um cachorro de estimação. Alguns moradores que convivem todo o dia com o movimento dos transeuntes pelos piques, contaram que passam pessoas a pé, de bicicleta, e a cavalo. Quando o nível da água do rio está baixo, passam também de motocicleta, e nos locais onde a fronteira é por terra passam de camionetas, caminhão e trator. Disseram que já viram caminhões de mudança, encostar próximo aos piques para descarregar a mudança inteira de famílias. Os objetos pequenos são transportados pelos carrinhos de mão até o outro lado, tais "façanhas" ocorrem com os moradores das duas localidades.

Nessas narrações, diversos fronteiriços, que residem próximos aos piques, afirmaram que muitos argentinos com dupla documentação, geralmente trabalhadores nas plantações de fumo nas chácaras de San Antonio, e trabalhadores das confecções deste município, se tratam no hospital e nos postos de saúde de Santo Antonio do Sudoeste. O mais inusitado foi ouvir relatos de que muitos dos que morreram no território brasileiro, foram transladados para a Argentina dentro dos caixões, e vice-

\footnotetext{
${ }^{13}$ Galletas: Se aplica a todo tipo de bizcochos pequeños dulces o salados, que se venden en paquetes muy consumidos.
} 
versa. Outro fato que provocou admiração, foi ouvir os populares contarem que muitas pessoas que morreram foram transportados sentados no meio de outras duas que a "escoravam", dentro dos automóveis. Colocavam boné ou chapéu na cabeça, e óculos como disfarces, alguns foram "passados" pelos piques, outros pela própria ponte que dá acesso às duas localidades. Tais fatos vem ao encontro do que escreveu Certeau (2013, p. 46) quando diz que, "sem cessar o fraco deve tirar partido de forças que lhe são estranhas. Ele o consegue em momentos oportunos [...] a sua síntese intelectual tem por forma não um discurso, mas a própria decisão, ato e maneira de aproveitar a "ocasião".

No dia a dia, o trabalhador de ambas as margens do Santo Antonio travam pequenas lutas silenciosas. Como de modo geral não pode contar com os serviços das municipalidades, apesar de ser cidadão com dupla cidadania, ele se vê obrigado a utilizar de "táticas" para resolver suas necessidades.

Fiz o trajeto diversos dias através das redes de piques interligadas com inúmeras bifurcações de infinitos piques que costeiam o Rio Santo Antonio.

Observei que a maneira de caminhar dos transeuntes, os movimentos corporais, os acenos como forma de cumprimento, os diálogos alegres e descontraídos, outras vezes breves e murmurados, os assovios, a espera em um lado da pinguela para o outro passar, constituem o cotidiano desses fronteiriços, entre um pique e outro entre uma barranca do rio e outra. No percurso, reverberavam as palavra de Bosi, (2004, p. 16) “[...] feliz o pesquisador que se pode amparar em testemunhos vivos e reconstituir comportamentos e sensibilidades de uma época".

Ao ouvir as pessoas que usavam os piques, entrei em um mundo próximo pela localização em que resido, mas distante de minha realidade social. Conforme relatos colhidos entre um pique e outro, o cotidiano de quem usa tais caminhos alternativos para se locomover entre Santo Antonio do Sudoeste e San Antonio é de medo, de histórias de mortes em que dizem não saber dados concretos, mas descrevem os corpos, as árvores onde as pessoas se enforcaram, a faca deixada para trás pelo assassino, os tiros ouvidos no meio da noite.

Os fatos narrados têm sempre a ausência de testemunhos dispostos a falar da mesma forma que a frase que aparece em vários depoimentos, como na frase "lá ninguém viu, mas fazem questão de dizer, de comentar o medo sentido, a curiosidade contida até o amanhecer". Apontam os locais em que as cruzes dos mortos nas duas margens estão localizadas, ascendem velas na sepultura do Tenente Araújo, vítima dos homens da Coluna Prestes, sem saber quem ele foi, que história há por trás da lápide. 
O mundo com o qual eles convivem, escondem histórias, experiências, tristezas, dificuldades, e medos. Inseguranças que se transformam em uma aventura diária para a maioria, mas mesmo assim continuam "a llenar silencios y boquetes por donde se les chorrea la vida" (KUSCH, 1986, p. 9).

Para outros, os piques fazem parte das vivências diárias e estão repetindo o que seus pais e avós fizeram. Usar os piques como caminhos alternativos para encurtar distâncias entre uma localidade e outra, mas principalmente para chibear produtos que garantem a manutenção familiar. Conforme Bosi (2004, p. 16) "do vínculo com o passado se extrai a força para a formação de identidade".

Parte dos entrevistados e muitos populares que conversaram comigo, expressaram a necessidade de falar dos antepassados, atribuindo-lhes papéis importantes de honra dentro de instituições militares, de educação, e até mesmo como justiceiros, jagunços e chibeiros em uma época que pouca gente residia na fronteira.

As palavras do depoente Anderson Borba remetem ao passado de seu avô quando narra que:

[...] por lei muitas coisas hoje são erradas, mas o chibo enfim, ele vem de muitos anos. No tempo de meu avô, depois de meu pai já se chibiaba, porque eles não tinham aquela liberdade também de passar na aduana com certas mercadorias pra consumo. Então se acostumava desviar as rotas, isso foi se caracterizando como chibo e até hoje continua assim. É uma bolsa de farinha que você passa, uma de batatinha, um botijão de gás, antigamente era uma lata de banha. Era um boi, um cavalo. Pequenas coisas, mas que significam bastante para nós (BORBA, 2015, não publicado ). ${ }^{14}$

Os depoimentos revelam que ele está na terceira geração de chibeiros, e o imposto que é deixado de recolher em ambos os países é ínfimo, se for calculado o valor dos objetos chibiados.

Me pergunto, será o gosto de aventurar-se na fronteira, desafiando as forças da gendarmería e da policia federal brasileira o que mantém três gerações no chibo? A instabilidade da oferta de trabalho seria um motivo de um chibeiro copiar a profissão do pai e do avô?

Passei horas entre um pique e outro, conversei com diversas mulheres com filhos pequenos pela mão. Algumas carregando bebês no colo. Uma gestante de oito meses, que após a conversa passou sobre a pinguela com a confiança de pisar em solo

\footnotetext{
${ }^{14}$ BORBA, A. Dissertação de Mestrado. Santo Antonio do Sudoeste, 2015. Não publicado.
} 
firme. Diversas mães atravessando os piques para acompanhar seus filhos até as escolas de ensino fundamental de Santo Antonio do Sudoeste.

Fiquei a pensar: É a falta de noção de perigo que faz com que mães grávidas e com filhos de três a oito anos atravessem o rio sobre pinguelas estreitas e sem nenhuma segurança? É o sentimento de banalidade que caracteriza o valor da vida? Ou simplesmente é a necessidade buscando formas mais eficientes de viver?

Pude constatar as tensões, os medos encobertos pelas prováveis necessidades que falam através do olhar apreensivo, da expressão do rosto, nos gestos nervosos, e das palavras faladas com cuidado, com certa desconfiança deixando transparecer a preocupação de estar fazendo algo ilícito, ao cruzar a pinguela para chegar ao território do outro país.

É interessante saber o que os depoentes falam sobre os chibos. Na memória do Sr. Elizandro Pellin ele diz lembrar que:

Esses brasileiros que entravam, derrubavam mato, plantavam, não tinha,
como vender na Argentina.[...] O meu pai comprava tudo. Você podia chegar
com qualquer coisa, com couro de jaguatirica, de onça, de quati, cavalo
velho, vacas, não ficava sem proposta. Aqui era um pequeno porto de troca.
Tem gente que sobrevivia disso. No tempo de meu pai, tinha os que
trabalhavam por dia com um cavalo e uma cangaia, puxando sacos de feijão,
ganhavam por viagem que faziam (PELLIN, 2015, não publicado).15

A memória está intimamente ligada à cultura e a história. Esquecer uma delas é deixar lacunas quando se está investigando acontecimentos experienciados por um determinado grupo, em determinado espaço geográfico. Mas há como falar de memória sem narrar à história?

A depoente Adelia Schwingel conta de como era na década de 1970, o comércio nas casas de comércio em San Antonio,

[...] Essa estrada aí que vai para Irigoyen, a cada dez metros tinha uma cantina. La na Telina, tinha uma grande cantina que vendiam farinha em sacos de 70 quilos, cebola, batatinha, azeite. Banha Trapona naquelas latas coisa mais linda do mundo que vinha de Córdoba. E traziam os contrabandos pro lado de cá. Vinham de longe para levar essas coisas, tudo pelos piques. Era sacrificoso (SCHWIN)GEL, 2015, não publicado. ${ }^{16}$

A entrevistada, não esconde o saudosismo, ao relatar o nome dos produtos, as cores das embalagens. Disse que às vezes lembra do pó de arroz da marca Lady, com

\footnotetext{
${ }^{15}$ PELLIN, E. Dissertação de Mestrado. Santo Antonio do Sudoeste, 2015. Não publicado.

${ }^{16}$ SCHWINGEL, A. Dissertação de Mestrado. Santo Antonio do Sudoeste, 2015. Não publicado.
} 
pluma de tecido acetinado para passar na pele, que deixava o rosto branquinho, e do perfume da colonia Siete Brujas que comprava no comércio argentino.

Apresentou-me a colcha de retalhos que disse acompanhá-la a mais de cinquenta anos. Passava a mão nos retalhos e dizia esse é de mucelina, este de veludo, este de percal, este é linho do bom, "olha menina, de saraça ${ }^{17}$ não tem, só usei retalhos nobres". Essa intimidade entre ações e narração permite ao sujeito criar os mecanismos a partir dos quais se passa do que é uma história individual e o que se inscreve na memória coletiva tal qual como indica Bosi (2003, p. 26) quando escreve que "só o objeto biográfico é insubstituível: as coisas que envelhecem conosco nos dão a pacífica sensação de continuidade."

Pude encontrar o sentido da citação de Bosi, observando as linhas retas dos retalhos costurados com primor na colcha de retalhos de dona Adelia Schwingel, estendida sobre a cama, especialmente para ser fotografada após a entrevista. Os desenhos dos pedaços de tecido, remetem as suas narrativas sobre vivências, as saudades, os amigos mortos nas emboscadas dos piques dos chibos. Nas palavras dela, "esse tempo bom que não volta mais" (SCHWINGEL, 2015, não publicado). ${ }^{18}$, ou quem sabe um "vivido" do tempo que foi. No mesmo sentido encontramos a fala do professor aposentado de San Antonio, Miguel Benitez que se refere à memória dizendo: "Vivir en la frontera es sólo para la gente, para los gobiernos no. Es una cosa, um limite de mapas políticos, no? Pero la frontera nuestra no existe, que pasamos y venimos como si antoja, incluso por los piques" (BENITEZ, 2015, não publicado) $)^{19}$.

A distância entre o que está escrito nas leis e o que se pratica no dia a dia da fronteira, é muito distante. As práticas, as vivências, os fazeres através dos piques, as relações que se dão entre um ir e vir constituem o conjunto de relações entre os fronteiriços de ambas as margens do rio Santo Antonio, observadas pela gendarmería e pela polícia brasileira. Tais ações, e práticas de sobrevivência que inclui os chibos, são protegidas pelos códigos de comunicação, velados entre um pique e outro, entre uma

\footnotetext{
${ }^{17}$ Saraça: Tecido de algodão fino.

${ }^{18}$ SCHWINGEL, A. Dissertação de Mestrado. Santo Antonio do Sudoeste, 2015. Não publicado.

${ }^{19}$ BENITEZ, m. Dissertação de Mestrado. Santo Antonio do Sudoeste, 2015. Não publicado.
} 
pinguela e outra, entre um canto do Sapucai $^{20}$ e outro para avisar que as autoridades estão se aproximando.

Segundo conversas informais de moradores quando das visitas aos piques, na fronteira seca, estes disseram que existe um comércio ilegal de grande monta que passa por tais piques, como por exemplo: cargas de camarão, de alpiste, ferro velho, chumbo de bateria, sem contar as dezenas de cabeças de gado que cruzam quase que diariamente pelos piques de terra, pois a acessibilidade é mais fácil do que por água.

Conforme os moradores das imediações dos piques, os proprietários das terras que fazem divisa com o Rio Santo Antonio, ou com a demarcação por terra até a fronteira com a Argentina, não são usuários dos piques, muitos deles, para não se incomodar com a passagem dos produtos chibeados, preferem fazer de conta que nada acontece. Outros são pagos pelos donos das cargas para não "abrir a boca". Ainda conforme os vizinhos dos piques, quem passa as cargas grandes, e que acumulam um valor significativo nos objetos passados pela fronteira, são pessoas que tem "grana, plata, capital de giro". Um dos moradores contou que na semana que antecedeu a minha visita a casa dele, foi apreendida uma carreta de alpiste. ${ }^{21}$ Obviamente não é um valor pequeno, mas segundo o mesmo morador a carreta já "se tinha pago faz tempo", com outras cargas que haviam cruzado a "linha" que demarca a fronteira.

Outro morador próximo a um pique de terra contou que há comerciantes, fazendeiros, políticos, que passam as mercadorias em grande quantidade. Quando o questionei sobre o porquê não são presos me explicou que a Polícia Federal e a Gendarmería Nacional, só podem apreender uma carga se no ato da apreensão tal carregamento estiver em cima da "linha" que demarca a fronteira. Caso contrário não, pois todo cidadão tem o direito de ir para onde quiser, e eles geralmente apresentam as notas das cargas.

Conforme depoimentos dos moradores e transeuntes anotados no Caderno de campo, eles afirmaram que muitos fazem chibo por uma questão cultural, que é o caso de alguns deles, para se divertir, pelo gosto da aventura, mas que é o chibo que não vai

\footnotetext{
${ }^{20}$ Sapucay: No dialeto mbya-guarani, proveniente da língua tupi, significa grito. O termo surgiu nas tribos guaranis, e os gritos simbolizavam emoções e momentos vividos pelos índios. Com o passar dos anos e a chegada dos jesuítas à região, o Sapucay foitomando outras formas e outros significados. A história conta que gritos eram usados como sinais, para que os chibeiros soubessem se podiam fazer a travessia ou não, se haviam no momento pessoas controlando o fluxo na fronteira.

${ }^{21}$ Alpiste: Grão da gramínea (Phalaris canariensis ). Alimento para pássaros domésticos engaiolados.
} 
dar prejuízo para ninguém, é uma bolsa de farinha, de batatinha, uma caixa de sabão, uma caixa de cerveja ou vinho.

Os piques não são usados apenas para o comércio ilícito, de grande ou menor monta, mas também como necessidade de encurtar a distância entre uma localidade e outra, tanto os piques nas imediações dos bairros que aproximam as pessoas de ambos povoamentos urbanos, bem como os que facilitam a aproximação das pessoas que residem na zona rural dos dois países.

Desse modo, entrar e sair dos limites fronteiriços não é visto como um ato insurgente aos poderes constituídos nos dois países, configura-se mais como prática cotidiana, historicamente inscrita e que assinala a vibração do que seja viver na fronteira. Estar ali implica em compreender que a amizade é um fator que transpõe qualquer documentação ou limite geográfico e que da mesma forma contornar os limites destes poderes constituídos pode, por vezes não ser vista como uma infração a lei.

Nesse sentido, é expressivo o depoimento do Senhor Andersom Borba que, ao referir-se ao movimento de entrar e sair da fronteira, diz: "você é tão acostumado com o povo, com a convivência, que você passa de um lado para o outro e você nem nota que está num país diferente” (BORBA, 2015, não publicado) ${ }^{22}$.

\section{CONSIDERAÇÕES FINAIS}

Conclui que o fronteiriço se identifica com as diferenças, e a possibilidade de conviver em meio a tais situações, de aprender com a gama de diversidades que fazem parte do cotidiano.

Neste cenário fronteiriço tudo se mistura no movimento do ir e vir diário, nas informações em portunhol, no câmbio negro que oscila nas mãos dos cambistas, comerciantes, e vendedores ambulantes. Nas placas dos carros com números e letras diferentes cruzando o posto fiscal e a ponte, as palavras escritas em português nas placas informativas de um lado do rio, e em castelhano no outro.

Se os silêncios persistem, se o tecido narrativo parece esgarçado, não é pela ausência de interação, mas pela sua profusão.

Entender o cotidiano das pessoas nas duas localidades desta fronteira, me fez perceber que esse limite não é simples de ser entendido como define a história oficial. A

\footnotetext{
${ }^{22}$ BORBA, A. Dissertação de Mestrado. Santo Antonio do Sudoeste, 2015, não publicado.
} 
fronteira não é somente demarcação de espaços territoriais, linhas divisórias entre as duas nações, compreendê-la envolve procurar sentidos assumidos pelos viventes das localidades. Neste sentido, o conceito é movediço, e adentrar neste terreno exigiu que enquanto pesquisadora colocasse sobre rasura representações que, como moradora do lugar, partilhava com os demais. Em tais movimentos, foi necessário estranhar e desnaturalizar as percepções do que significava ser fronteiriça.

Neste contexto é conveniente demarcar que estudar esta fronteira se assemelhou a caminhar dentre os piques em que a cada bifurcação novos caminhos se apresentam. Nesta percepção, a fronteira é lugar dos encontros e desencontros, da proximidade e da lonjura, do conhecido e do desconhecido, da dificuldade e da facilidade, das idas e vindas. Do trânsito, do movimento que gera movimento.

No decorrer do trabalho fiquei atenta, a voz dos entrevistados, e sobretudo ao que deixaram transparecer nos discursos e na expressão corporal dos narradores.

Que tipo e de quem são as vozes, que se renovam junto ao murmúrio das águas do Santo Antonio, que correm apressadas como para acompanhar as inovações de um tempo que chega com seus modismos, tecnologias e desafios? O momento atual deixará possibilidades para a evocação da memória dos habitantes das duas localidades?

Concluí que este trabalho amplia os questionamentos iniciais pois o ambiente pesquisado demanda aprofundamento nas investigações. Apresenta as nuances que consegui visualizar, mas há todo um campo de possibilidades que se insinuam para trabalhos posteriores.

\section{REFERÊNCIAS}

AULETE, Caldas. Novíssimo Aulete dicionário contemporâneo da língua portuguesa/Caldas Aulete: [organizador Paulo Geiger]. Rio de Janeiro. Lexikon. 2011. 1488p.

BOSI, Eclea. Memória e Sociedade: Lembranças de Velhos. São Paulo. Companhia das Letras. 2004.

CERTEAU, Michel de. A invenção do cotidiano: 1. Artes do fazer. 20. ed. Petrópolis, RJ: Vozes, 2013.

CHAUÍ, Marilena. Convite à Filosofia. 12. ed. 6. impressão. São Paulo: Ed. Ática, 2002.

JORNAL Impacto On Line. Disponível em: https://www.facebook.com/JornalImpacto Online. Acesso em: 02 de fevereiro de 2016. 
KUSCH, Rodolfo. América Profunda. 1986. $3^{\mathrm{a}}$. Ed. Argentina.

MAFFESOLI, Michel. A Parte do Diabo. Tradução de Clóvis Marques. Editora Record. Rio de Janeiro. São Paulo. 2004.

MARI, Marilce. No Silêncio da Fronteira. RIAGRAF. Santo Antonio do Sudoeste. 2002.

MARTINS, José de Souza. Fronteira: a degradação do Outro nos confins do humano. São Paulo: Contexto, 2009.

MORAES, Manoel Pereira. Álbum Fotorevista Municipal. Tipografia Santa Cruz. Curitiba-PR, 1974.

SCARABOTTO, Ivonete Zanini. Questão Sócio-Ambiental e desenvolvimento regional. Santo Antonio do Sudoeste. GRAFIT. 2007.

WOODWARD, Kathryn. Identidade e Diferença: uma introdução teórica e conceitual. In. SILVA, Tomaz Tadeu da. (org) Identidade e Diferença: a perspectiva dos Estudos Culturais. Petrópolis: Vozes, 2000. 